IMDS

117,9

1842

Received 28 June 2016

Revised 11 September 2016

16 November 2016

27 February 2017

10 May 2017

Accepted 11 May 2017

\section{Three-level supply chain coordination of fresh agricultural products in the Internet of Things}

\author{
Bo Yan, Xiao-hua Wu, Bing Ye and Yong-wang Zhang \\ School of Economics and Commerce, South China University of Technology, \\ Guangzhou, China
}

\begin{abstract}
Purpose - The Internet of Things (IoT) is used in the fresh agricultural product (FAP) supply chain, which can be coordinated through a revenue-sharing contract. The purpose of this paper is to make the three-level supply chain coordinate in IoT by considering the influence of FAP on market demand and costs of controlling freshness on the road.

Design/methodology/approach - A three-level FAP supply chain that comprises a manufacturer, distributor, and retailer in IoT is regarded as the research object. This study improves the revenue-sharing contract, determines the optimal solution when the supply chain achieves maximum profit in three types of decision-making situations, and develops the profit distribution model based on the improved revenuesharing contract to coordinate the supply chain.

Findings - The improved revenue-sharing contract can coordinate the FAP supply chain that comprises a manufacturer, distributor, and retailer in IoT, as well as benefit all enterprises in the supply chain.

Practical implications - Resource utilization rate can be improved after coordinating the entire supply chain. Moreover, loss in the circulation process is reduced, and the circulation efficiency of FAPs is improved because of the application of IoT. The validity of the model is verified through a case analysis.

Originality/value - This study is different from other research in terms of the combination of supply chain coordination, FAPs, and radio frequency identification application in IoT.
\end{abstract}

Keywords Internet of Things, Revenue-sharing contract, Fresh agricultural product,

Supply chain coordination

Paper type Research paper

\section{Nomenclature}

\begin{tabular}{|c|c|c|c|}
\hline$q$ & $\begin{array}{l}\text { Order quantity of retailers } \\
\text { to distributors }\end{array}$ & $c_{3}$ & $\begin{array}{l}\text { Marginal cost of order for } \\
\text { the manufacturer }\end{array}$ \\
\hline \multirow[t]{2}{*}{$w_{1}$} & Unit wholesale price of products & $c_{4}$ & Costs of IoT \\
\hline & for the distributor & $c_{5}$ & Unit cost for the RFID tags \\
\hline \multirow[t]{2}{*}{$w_{2}$} & Unit wholesale price of products & $c_{6}$ & Unit maintenance cost for Io $\mathrm{T}$ \\
\hline & for the manufacturer & $c_{7}$ & Cost of the IoT hardware, \\
\hline$p$ & Retail prices & & middleware, and software \\
\hline$c_{1}$ & $\begin{array}{l}\text { Marginal cost of order for } \\
\text { the retailer }\end{array}$ & $c_{8}$ & $\begin{array}{l}\text { Other relevant cost (including } \\
\text { business processes, services }\end{array}$ \\
\hline$c_{2}$ & $\begin{array}{l}\text { Marginal cost of order for } \\
\text { the distributor }\end{array}$ & $c(\theta)$ & $\begin{array}{l}\text { training, and education) } \\
\text { Cost of freshness control }\end{array}$ \\
\hline
\end{tabular}

(C) Bo Yan, Xiao-hua Wu, Bing Ye and Yong-wang Zhang. Published by Emerald Publishing Limited. This article is published under the Creative Commons Attribution (CC BY 4.0) licence. Anyone may reproduce, distribute, translate and create derivative works of this article (for both commercial \& non-commercial purposes), subject to full attribution to the original publication and authors. The full terms of this licence may be seen at: http://creativecommons.org/licences/by/4.0/legalcode 


$\begin{array}{lll}\alpha \cdot c(\theta) \text { and } & \text { Cost of freshness control shared } & \pi \\ \beta \cdot c(\theta) \text { where } & \text { by the retailer and distributor, } & \varphi_{1} \\ \alpha+\beta=1 & \text { where } \alpha+\beta=1 \\ \rho & \text { Technical complexity of the IoT } & \varphi_{2} \\ \gamma & \text { application }(0,1) & \\ & \text { RFID tag recycling rate }\end{array}$

$\alpha \cdot c(\theta)$ and Cost of freshness control shared $\pi$

RFID tag recycling rate
Total profits of the supply chain

Revenue sharing rate for the

retailer $(0,1)$

Revenue sharing rate for the

distributor $(0,1)$

\section{Three-level supply chain coordination}

\section{Introduction}

Fresh agricultural product (FAP) is a special type of perishable product that has a random life cycle and with a demand that is affected by freshness. Approximately 500 million tons of fresh fruits, vegetables, and nuts are produced annually and represent a large, important, and expanding industry. Approximately 25-30 percent of the total production is discarded after harvest because of problems during circulation (Donis-González et al., 2014). Approximately 12 million tons of fruits and 13,000 tons of vegetables are wasted in China annually; the postpartum loss rate of fruits and vegetables is as high as 25 percent and the economic loss is over 15.4 billion dollars (Lin and Fan, 2014). The transport of FAPs faces problems, such as large losses, low efficiency, and high cost. These issues have attracted considerable attention from all sectors of society.

The FAP supply chain is different from the general supply chain with regard to the freshness of agricultural products. With the reduction of freshness, although the product has not been completely spoiled, its value and market demand will continue to decline. The FAP supply chain considers the product freshness and proposes higher requirements for the storage, transportation, processing, and other aspects of the product, compared with the general supply chain. The research of radio frequency identification (RFID) in the field of supply chain focuses on information sharing and product security; however, the influence of freshness on the supply chain decision and the control of freshness in the actual production are not considered. Moreover, mastering the real-time information change of product freshness, the relationship between freshness control cost and freshness, and the effect on the optimum freshness are ignored. These limitations lead to the inability of the research results of the general supply chain to be directly applied to the FAP supply chain. Therefore, this study introduces the concept of the Internet of Things (IoT); proposes high requirements for the production, transportation, quality and safety management, and traceability of FAPs; and explains the process of obtaining freshness information and controlling freshness based on the operation mode of the three-level supply chain. Furthermore, this study proposes the strategy of supply chain coordination under the environment of the IoT, which is useful for the application of the IoT technology in the supply chain management of FAPs. This strategy has theoretical and practical significance.

IoT can combine technologies, such as RFID, sensors, and the internet, to realize intelligent identification and management, thereby providing significant opportunities in developing the FAP supply chain (Hong et al., 2011). Gunasekaran et al. (2016) investigated the effect of big data and predictive analytics assimilation on the supply chain and organizational performance from the resource-based view. The characteristics of the FAP supply chain in IoT include seamlessness between upstream and downstream enterprises in the supply chain, information sharing, strong ability to resist risks, ideal supply chain system, few redundant links in the supply chain, and high organization (Verdouw et al., 2016). As a related technology of IoT, RFID may obtain and intelligently control temperature and humidity during transport (Yan et al., 2015); this approach can effectively reduce the FAP losses and is a key point for following and reviewing agricultural products (Yu and Nagurney, 2012). Furthermore, IoT also connects devices with the internet or sensor networks to achieve intelligent management, such as temperature and humidity 
IMDS 117,9

1844

monitoring, transportation tracking, and timely regulation control. Therefore, the FAP supply chain, which is closely combined with IoT, is an important development trend in the future.

\section{Literature review}

An increasing number of scholars have focused on the FAP supply chain, supply chain coordination, and supply chain management in IoT.

\subsection{FAP supply chain}

The FAP plays an important role in people's daily lives, and whether the FAP supply chain is good or not is closely related to the happiness of the people. Therefore, many scholars have conducted in-depth research in this area (Ahumada et al., 2012; Yu et al., 2012; Cai et al., 2013; Narsimhalu et al., 2015). Nahmias (1982) divided the perishable products, which include the FAP, into products with stochastic or fixed life cycles.

With regard to the research on ordering FAP supply chain, most scholars consider the characteristics of freshness. Shen et al. (2011) studied the ordering strategies of retailers on the prediction of member cooperation in a two-level supply chain composed of suppliers and retailers. The authors suggested that the prediction of cooperation reduces the cost of the supply chain. Lee and Dye (2012) focused on the optimal ordering strategy and optimal investment of retailers in preservation, wherein goods are partly in short supply, and demand depends on inventory. Sana (2010) studied the optimal ordering strategy within the multi-product inventory model based on previous research, in which demand depends on the work of retailers.

A considerable amount of research on the pricing of FAP supply chain focuses on freshness, and offered optimal strategies regarding quality and quantity wastage. For example, Qin et al. (2014) investigated pricing and decision of batch ordering, and suggested that demand is correlated to quality, price, and retailer inventory. They also offered optimal strategies regarding quality and quantity wastage. Cai and Zhou (2014) researched on the distribution of multiple fresh produce; they found that compared to domestic sales, international sales are easily disturbed by basic transport networks. Thus, they explored export waiting time and pricing from the perspectives of order and stock manufacturing.

But all of studies did not consider how to control freshness in actual production, how to catch timely change information of product freshness, the relationship between the freshness and control cost and influence to the optimal freshness.

\subsection{Supply chain coordination}

Members of the supply chain pursue the maximization of their respective interests, and the target is often conflict; thus, the coordination of the operational strategy between the members becomes difficult (Choi and Cheng, 2011). The method of coordinating the supply chain has become one of the leading issues in the supply chain management research. Supply chain coordination is the key to supply chain cooperation, and the supply chain coordination mechanism is designed to improve the overall efficiency of the supply chain system (Arshinder et al., 2011). Yang and Zhao (2011) explained that a contract is a common and effective supply chain coordination mechanism that has been extensively studied in recent years. A proposed contract is based on two key mechanisms: additional ordering cost for the retailer and price discount offered by the supplier to the retailer (Bellantuono et al., 2011).

Höhn (2010) explained that a supply chain contract can be divided into four main types: wholesale price, buy back, revenue-sharing, and quantity flexibility contracts. Wholesale price and buy back contracts are the most common types of contracts; whereas revenue-sharing and quantity-flexibility contracts study member income and product quantity, respectively, which are the core content in the supply chain. A revenue-sharing 
contract plays a good role in reducing the conflict between suppliers and retailers (Zhang et al., 2012). However, this contract is only a share of revenue but not a cost-sharing contract to constraint; scholars mainly focused on the industrial supply chain coordination with revenue-sharing contract or improved it (Krishnan and Winter, 2011; Ouardighi, 2014). Lohmann (2010) compared the optimal solutions of buy-back strategy, joint pricing strategy, and earning sharing strategy in his research on supply chain coordination given the demand under the influence of pricing and retailer work. In comparison, earning sharing is more realistic than buy-back, because the temporary freshness of produce leads to a near-zero value of unfresh produce, which is unsuitable for buy-back.

\subsection{Supply chain management in IoT}

IoT is a network of real-world objects linked by RFID, infrared sensors, and global positioning system (GPS) to exchange information and communication, as well as achieve intelligent recognition, positioning, tracking, and monitoring management. Voigt and Inderfurth (2011) and Al-Busaidi et al. (2016) explained that IoT management models provide supply chain information, integrated resources, breakthrough barriers, and effective information that supports platforms for enterprises. Li et al. (2016) integrated the wireless sensor network into IoT for military sensing and tracking, target tracking, and environment monitoring. Maralit et al. (2013) determined that food traceability provides a robust method of assessment for species identification and authenticity testing of commercial fishery products. Tendyck (2015) considered that information on the numerous potential automotive applications improved keyless entry systems and connected applications in vehicles, such as driver's health monitoring and vehicle controlling.

The supply chain in the IoT environment can achieve intelligent production cultivation and real-time control in transit, safety and quality management, and traceability, thereby reducing the rate of damage incidents and ensures the supply chain information sharing. It is conducive to the coordination of the supply chain (Yan et al., 2016). In addition, the security management of FAP demands customer health protection, social stability, and efficient operation of the FAP supply chains. The introduction of IoT improves the approach and efficiency of the quality supervision department of the government, as well as guarantees the integration of quality management inside the FAP supply chain in the aspect of information and technology. Studies on the combination of IoT and supply chain management are limited, with the exception of RFID technology, which is extensively used in IoT. For example, RFID technology has been used in the manufacturing industries to create an RFID-enabled ubiquitous environment, where ultimate real-time advanced production planning and scheduling are achieved with the goal of collective intelligence (Zhong et al., 2015). Lu et al. (2016) demonstrated that automated guided vehicles' positioning could be enhanced through RFID technology. Ruiz-Garcia and Lunadei (2011) discussed the opportunity and challenge of the FAP supply chain based on RFID technology. Grunow and Piramuthu (2013) studied the application of RFID technology in the FAP supply chain. However, most studies focused on RFID utilization to shorten supply lead time, improve ordering accuracy, and reduce the error rate and loss of inventory in the FAP supply chain (Rekik et al., 2009; Heese, 2011). These studies have failed to consider how the use of the IoT technology affects the supply chain coordination with the overall profit of the supply chain.

Many studies have focused on the supply chain coordination of FAP and IoT in the field of agricultural products. However, most of these studies focus on either the supply chain coordination or IoT engineering applications. The traditional revenue-sharing contract considers only income sharing but lacks cost sharing. Thus, the current study combines these elements and introduces IoT into the FAP supply chain. This study uses a three-level supply chain that comprises a manufacturer, distributor, and retailer in IoT as the research objects to consider the coordination problem of the supply chain under the condition of price and freshness, thereby affecting the market demand. Moreover, this study determines the

\section{Three-level supply chain coordination}


IMDS

117,9

1846

optimal solution when the supply chain achieves maximum profit in the three types of decision-making situations: centralized, decentralized, and revenue-sharing contracts. The current study also establishes the profit distribution model based on the improved revenue-sharing contract, which considers cost sharing and calculates the contract parameter range of the FAP supply chain. This study also analyzes the meaning of the applications of IoT in FAP supply chain and proposes coordination strategy based on the revenue-sharing contract. This work is of theoretical and practical significance because it explores the applications of IoT in the supply chain of FAPs.

\section{Model descriptions and introduction of symbols}

The three-level FAP supply chain comprises a manufacturer, distributor, and retailer. Figure 1 shows the FAP supply chain model that operates without IoT. The manufacturer is the farmer or agricultural producer cooperatives. The retailer, such as agricultural cooperatives, orders FAP from the distributor, and the distributor orders from the manufacturer based on the retailer's order. Verdouw et al. (2016) described that under decentralized decision making, only the retailer understands the market demand, and the distributor merely obtains information from the retailer. Similarly, the manufacturer can speculate the market demand based on the information from the distributor because the information flow of the supply chain is unidirectional (Yu and Nagurney, 2012). The supply chain information system can achieve supply chain information sharing under a centralized decision making.

However, Yan et al. (2015) pointed out supply chain informatization and intellectualization have not been well achieved. This problem can be addressed if IoT is introduced into the supply chain management (see Figure 2). In IoT, the retailer orders from the distributor, and the distributor orders FAP from the manufacturer based on the retailer's order. IoT ensures intelligent production, transportation, distribution, sales testing, traceability, and other supply chain activities (Al-Busaidi et al., 2016; Ruiz-Garcia and Lunadei, 2011). By connecting with the information systems of government regulators, the supply chain information system achieves supply chain information sharing and ensures efficiency in all aspects of the quality inspection of FAP, as well as the publication and query of quality information on FAP.

IoT has many benefits, although it inevitably brings additional cost, such as maintenance and label use (the core cost). Whether the FAP supply chain can be coordinated again in IoT is a problem worthy of attention. This study mainly explores a three-level FAP supply chain in IoT. This supply chain comprises a manufacturer $M$, distributor $D$, and retailer $R$. A singlecycle model and retailer order at the beginning of the sales cycle is considered.

The following assumptions are provided:

(1) Supply chain business transactions are limited to the upstream and downstream of the supply chain, and the manufacturer is unable to supply directly to retailers.

(2) $\theta$ is the freshness factor for FAP, which decreases with the increase of transit or storage time. Transportation from the manufacturers to distributors is often by bulk, and transportation time is stable. Lin et al. (2011) explained that

Figure 1.

Three-level supply chain of the FAP operation model without IoT

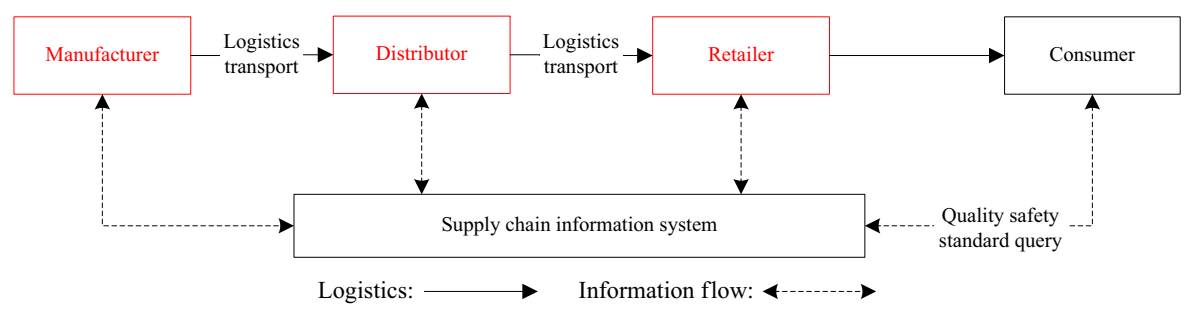




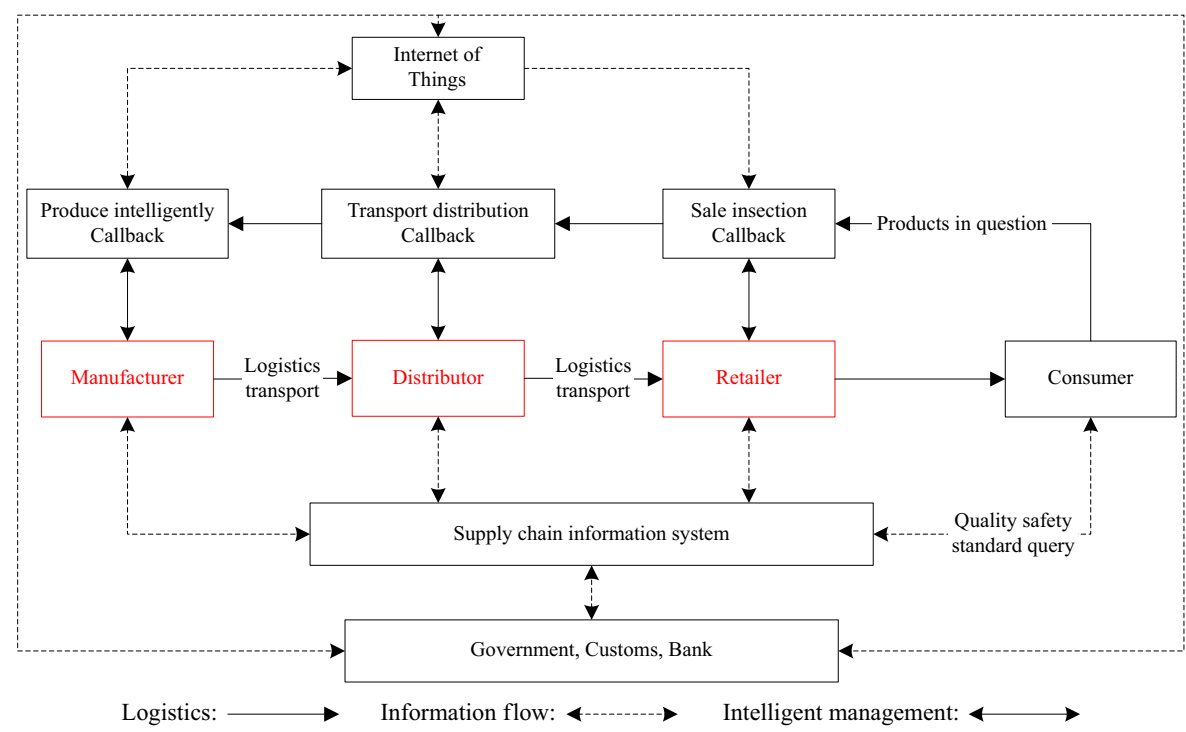

Three-level supply chain coordination

1847

Figure 2.

Three-level supply chain of the FAP operation model in IoT

$\theta(t)=1-\left(t+t_{0}\right)^{2} /\left(T^{2}\right)$ is the function of freshness, where $t_{0}$ is the transit time from the manufacturers to distributors, $T$ is the life cycle of FAPs, and $t$ is the transportation delivery time from the distributors to retailers.

(3) The freshness of agricultural products affects market demand. The demand of FAP is considerable when the freshness quality is high. Therefore, the retailers have good sales.

(4) To ensure the freshness of each batch of FAP, the retailer should bear the cost of freshness control $c(\theta)$, and $c^{\prime}(\theta)>0, c^{\prime \prime}(\theta)>0$. The manufacturer bears the cost of FAP by using IoT, which includes the cost of hardware, middleware, and software; cost of maintenance; and an RFID tag. In the improved revenue-sharing contract, the cost of freshness control, which is $\alpha \cdot c(\theta)$ and $\beta \cdot c(\theta)$, where $\alpha+\beta=1$, is shared by the retailer and distributor.

(5) This study analyzes FAP, which has a short life cycle, without considering the cost of inventory. The surplus product salvage value of a sales cycle is 0 . The cost of fixed facilities, such as IoT, is not considered because its application is constant and does not affect decision making. All decision makers are risk neutral and rational without regard to stock losses.

Nomenclature shows the other variables used in the model.

Moreover, $I$ represents the centralized decision-making supply chain, $S$ represents the decentralized decision-making supply chain, and $C$ represents the decentralized decisionmaking supply chain under contract. In the centralized decision-making supply chain, the manufacturer, distributors, and retailers are consistent with the interests; the optimal order quantity under the stochastic demand of the market is determined to maximize the total profit of the FAP supply chain. In the decentralized decision-making supply chain, the manufacturers, distributors, and retailers are different decision makers who maximize their respective profits. However, in the decentralized decision-making supply chain under contract, the retailers obtain the products with low wholesale prices from the distributor but share a certain percentage of the proceeds with distributors. Moreover, distributors share a certain percentage of their income with the manufacturer to obtain low wholesale price. 
IMDS

117,9

1848

\section{Supply chain coordination of FAP in IoT}

The introduction of IoT provides technical support for tracking and tracing the path of FAPs in the supply chain, improves supply chain operational efficiencies in the following methods, and reflects the sustainable development of agriculture:

(1) Intelligent production and cultivation: the production and cultivation of FAPs are the sources of the entire supply chain. The application of IoT monitors the growth environment of FAPs (including temperature, humidity, light, soil $\mathrm{pH}$, and fertilizer concentration) for real-time adjustment and whether the acts of production (e.g. application of fertilizer and pesticide) reduce soil contamination to a minimum. Moreover, IoT substantially maintains soil fertility.

(2) Control of cold-chain logistics in transit: IoT is used in FAPs' cold-chain logistics process to monitor the status of vehicles in transit and identify the security of drivers through GPS, geographic information system, and identification systems. IoT also ensures that information on door control, compartment environment, and status of FAPs can be collected and controlled in real-time RFIDs and wireless sensor networks to guarantee the safety of FAPs in transit. During these processes, the waste of resource would achieve the minimum state with the least environmental cost and obtain the optimal allocation of the resource.

(3) Management and traceability of quality and safety: the quality and safety management of FAPs in IoT includes external supervision from government departments and the supply chain internal control. Government regulators strengthen the quality safety supervision of FAPs by arranging the IoT facilities, including sensing devices, RFID devices, and video surveillance equipment, and network in the inputs, thereby producing an environment, production processes, packaging, labeling, and market access. However, the supply chain member uses IoT to arrange production following the quality and safety standards of FAPs to control the ecological environment for growth, coldchain transport environment, and inventory environment of FAPs to ensure quality and high yield.

\subsection{Model}

The function of the market demand is $x=y(p, \theta)+\eta, p \in\left(c, p_{0}\right), \theta \in\left(\theta_{0}, 1\right)$, where $p_{0}$ is the maximum retail price, that is, sales $y\left(p_{0}, \theta\right)=0$, when the retail price is equal to $p_{0}$; and $\theta_{0}$ is the lowest freshness quality of FAP that customers can accept when $\theta<\theta_{0}, y(\phi, \theta)=0$. Assuming that the demand function in the form of addition is $y(p, \theta)=a+k \cdot \theta-l$. $p$ (He et al., 2009), in which $a, k, l>0$, the cost function of controlling freshness during transport is set to $c(\theta)=\left(\sigma \theta^{2}\right) /(2), \sigma>0$ (Lohmann, 2010). $\eta$ is a random factor, which means that apart from price and freshness, other factors (e.g. policy, consumption concept, and anti-factors that influence the market demand) are not emphasized in this study. Moreover, $\eta$ follows an exponential distribution. Thus, $f(\eta)=\lambda e-{ }^{\lambda \eta}, F(\eta)=1-\mathrm{e}^{-\lambda \eta}$, $F^{-1}(z)=-(1 / \lambda) \ln (1-z), \lambda>0,0<z<1$. Thereafter, the expected FAP sales amount is expressed as follows:

$$
\begin{aligned}
S(p, q, \theta) & =E[\min (q, x)]=\int_{0}^{q} x \cdot f(x-y(p, \theta)) d x+q \cdot \int_{q}^{+\infty} f(x-y(p, \theta)) d x \\
& =q-\int_{y(p, \theta)}^{q} F(x-y(p, \theta)) d x=q-\int_{0}^{q-y(p, \theta)} F(x) d x .
\end{aligned}
$$


4.2 Decision analysis of supply chain under the condition of centralized decision making

The manufacturer, distributor, and retailer are consistent main bodies under a centralized decision making. A unique decision maker in the FAP supply chain determines the optimal order quantity based on the market's stochastic demand. The supply chain determines the optimal order quantity $q$ and selling price $p$ by arranging the production, transport, and distribution to earn the best overall profit. Therefore, centralized decision making does not consider transfer payments among the members of the supply chain, and the total profit of the FAP supply chain is as follows:

$$
\pi_{I}=p \cdot S(p, q, \theta)-\left(c_{1}+c_{2}+c_{3}\right) \cdot q-\rho \cdot\left[c_{6}+c_{7}+c_{8}+c_{5} \cdot(1-\gamma)\right] \cdot q-c(\theta) .
$$

The total profit comprises four parts: sales revenue $p S(p, q, \theta)$, the cost of ordering and producing $\left(c_{1}+c_{2}+c_{3}\right) \cdot q$, costs of the IoT maintenance and RFID tag $\rho \cdot\left[c_{6}+c_{7}+c_{8}+c_{5} \cdot(1-\gamma)\right] \cdot q$, and cost of control freshness $c(\theta)$. Demand $c_{4}=\rho \cdot\left[c_{6}+c_{7}+c_{8}+c_{5} \cdot(1-\gamma)\right]$, where $\rho$ is the technical complexity of the IoT application. If an average of 20 units of products use the RFID tags, then the technical complexity of the IoT application is 1/20. Assuming $c=c_{2}+c_{3}+c_{4}+c_{1}$, the following equation is as follows:

$$
\pi_{I}=p \cdot S(p, q, \theta)-c \cdot q-c(\theta) .
$$

By calculating the second-order partial derivative of the total profit on freshness $\theta$, order quantity $q$, and retail price $p$, we can obtain $\left(\partial^{2} \pi_{I}\right) /\left(\partial p^{2}\right)=-2 \cdot l \cdot F[q-y(p, \theta)]-p \cdot l^{2} f[q-y(p, \theta)]$ $<0,\left(\partial^{2} \pi_{I}\right) /\left(\partial \theta^{2}\right)=-p \cdot k^{2} f[q-y(p, \theta)]-\sigma<0,\left(\partial^{2} \pi_{I}\right) /\left(\partial q^{2}\right)=-p \cdot f[q-y(p, \theta)]<0$, thereby showing that $\pi_{I}$ is a strictly concave function to $\theta, q$, and $p$. That is, the optimal solutions for $\theta, q$, and $p$ exist. Assuming $\left(p_{I}^{*}, \theta_{I}^{*}, q_{I}^{*}\right)$ is the solution, the total profit of the optimal supply chain is as follows:

$$
\left\{\begin{array}{l}
\frac{\partial \pi_{I}}{\partial \theta_{I}^{*}}=p \cdot \frac{\partial S\left(p, q, \theta_{I}^{*}\right)}{\partial \theta_{I}^{*}}-c^{\prime}\left(\theta_{I}^{*}\right)=0 \\
\frac{\partial \pi_{I}}{\partial p_{I}^{*}}=S\left(p_{I}^{*}, q, \theta\right)+p_{I}^{*} \cdot \frac{\partial S\left(p_{I}^{*}, q, \theta\right)}{\partial p_{I}^{*}}=0 \\
\frac{\partial \pi_{I}}{\partial q_{I}^{*}}=p \cdot \frac{\partial S\left(p, q_{I}^{*}, \theta\right)}{\partial q_{I}^{*}}-c=0 .
\end{array}\right.
$$

The optimal order quantity of the centralized decision making is calculated by using the following equation as follows:

$$
q_{I} *=F^{-1}\left(1-\frac{c}{p}\right)+y(p, \theta) .
$$

$\pi_{I}=(p-c)(a+k \cdot \theta-l \cdot p)+(p-c+(\ln p-\ln c) c / \lambda)-\left(\sigma \theta^{2} / 2\right)$ is solved, such that a unique optimal solution freshness $\theta_{I}^{*}$ and retail price $p_{I}^{*}$ exist to satisfy $\left(\partial \pi_{I}\right) /\left(\partial \theta_{I}{ }^{*}\right)=k(p-c)-\sigma \cdot \theta_{I}{ }^{*}=0$ and $\theta_{I}^{*}=(k(p-c)) /(\sigma)$. These values are substituted into $\pi_{i}$.

$$
\pi_{I}=(p-c)\left(a+k^{2} \cdot \frac{p-c}{2 \sigma}-l \cdot p\right)+\frac{p-c+(\ln p-\ln c) c}{\lambda},
$$

We can determine:

$$
\begin{aligned}
\frac{\partial \pi_{I}}{\partial p_{I}^{*}} & =a+\frac{k^{2}\left(p_{I}^{*}-c\right)}{\sigma}-l p_{I} *+\left(\frac{k^{2}}{\sigma}-l\right)\left(p_{I}^{*}-c\right)+\frac{1}{\lambda}+\frac{c}{\lambda p_{I}^{*}}-\frac{k^{2}}{\sigma}\left(p_{I}^{*}-c\right) \\
& =a+\frac{1}{\lambda}-\left(\frac{k^{2}}{\sigma}-l\right) c+\left(\frac{k^{2}}{\sigma}-2 l\right) p_{I}^{*}+\frac{c}{\lambda} \frac{1}{p_{I}^{*}}=0 .
\end{aligned}
$$


IMDS

117,9

1850

Determining the optimal retail price is easy:

$$
p_{I} *=\frac{-\left[a+\frac{1}{\lambda}+\left(l-\frac{k^{2}}{\sigma}\right) c\right] \pm \sqrt{\left[a+\frac{1}{\lambda}+\left(l-\frac{k^{2}}{\sigma}\right) c\right]^{2}-4\left(\frac{k^{2}}{\sigma}-2 l\right) \frac{c}{\lambda}}}{2\left(\frac{k^{2}}{\sigma}-2 l\right)}
$$

The requirements of the supply chain coordination show that the supply chain contract could coordinate the supply chain and further achieve the best whole FAP supply chain when the demand is affected by price and freshness. The order quantity and sales price achieve coordination and satisfy Equation (4).

\subsection{Optimal decision of non-contractual supply chain under a decentralized decision- making condition}

Under a decentralized decision-making condition, the retailer determines the order quantity $q$ based on the random market demand; the distributor maximizes profits only when he/she fulfills the order quantity $q$ of the retailer. The distributor orders $q$ units of FAP from the manufacturer with the wholesale price of $w_{2 S}$ and determines the appropriate wholesale prices $w_{1 S}$ to maximize his/her own profit. The manufacturer has to meet the distributor demand and determine the wholesale price $w_{2 S}$ to maximize his/her own profit. Therefore, the profits of the retailer, distributor, and manufacturer are calculated as follows under a decentralized decision making:

$$
\left\{\begin{array}{l}
\pi_{R S}=p \cdot S(p, q, \theta)-\left(c_{1}+w_{1 S}\right) \cdot q-c(\theta) \\
\pi_{D S}=\left(w_{1 S}-c_{2}-w_{2 S}\right) \cdot q \\
\pi_{M S}=\left(w_{2 S}-c_{3}-c_{4}\right) \cdot q .
\end{array}\right.
$$

The optimal order quantity of the non-contract supply chain under the condition of a decentralized decision making should be based on the derivation process of a centralized decision making as follows:

$$
\begin{gathered}
q_{S}^{*}=F^{-1}\left(1-\frac{c_{1}+w_{1 S}}{p}\right)+y(p, \theta) \\
\theta_{s}^{*}=\frac{k\left(p-c_{1}-w_{1 S}\right)}{\sigma} \\
p_{S}^{*}=\frac{-\left[a+\frac{1}{\lambda}+\left(l-\frac{k^{2}}{\sigma}\right)\left(c_{1}+w_{1 S}\right)\right]+\sqrt{\left[a+\frac{1}{\lambda}+\left(l-\frac{k^{2}}{\sigma}\right)\left(c_{1}+w_{1 S}\right)\right]^{2}-4\left(\frac{k^{2}}{\sigma}-2 l\right) \frac{\left(c_{1}+w_{1 S}\right)}{\lambda}}}{2\left(\frac{k^{2}}{\sigma}-2 l\right)} .
\end{gathered}
$$

Proof: see the Appendix.

We could further determine the optimal profit $\pi_{R S}^{*}$ and $\pi_{D S}^{*}$ of the supply chain members.

We determine the relationship between the optimal order quantity $q_{I}^{*}$ of the supply chain under a centralized decision-making condition and the optimal order quantity $q_{S}^{*}$ of the decentralized supply chain under a decentralized decision-making condition by comparatively analyzing Equations (7) and (5). The wholesale price $w_{1 S}$ must be larger than the sum of the order price of the distributor and cost of the manufacturer, including the production and maintenance costs of using IoT per unit because the distributor must earn a 
profit, $c_{1}+w_{1 S}>c=c_{1}+c_{2}+c_{3}+c_{4}$, such that $1-c / p>1-\left(c_{1}+w_{1 S}\right) / p$ is positive. Thereafter, we obtain $q_{I}^{*}>q_{S}^{*}\left(F^{-1}(x)\right.$ is an increasing function), that is, the optimal order quantity $q_{s}^{*}$ of the decentralized supply chain under a decentralized decision-making condition is less than the optimal order quantity $q_{I}^{*}$ of the supply chain under a centralized decision-making condition. Moreover, the decentralized decision-making strategy could not achieve supply chain coordination.

\subsection{Optimal decision of the supply chain based on improved revenue-sharing contract under a decentralized decision-making condition}

Benefit sharing and cost sharing are considered in the improved revenue-sharing contract. Assumption 4 states that the cost of freshness control, which is $\alpha \cdot c(\theta)$ and $\beta \cdot c(\theta)$, where $\alpha+\beta=1$, is shared by the retailer and distributor. The retailer will return $1-\varphi_{1}$ proceeds to the distributor. The retailer acquires FAP with a low wholesale price $w_{1}$ after obtaining $1-\varphi_{1}$ proceeds of the retailer. The distributor would obtain a low wholesale price $w_{2}$ from the manufacturer and share the $1-\varphi_{2}$ proceeds with the manufacturer as a return. By combining this condition with Assumption 4, we can obtain the profit function of the supply chain based on an improved revenue-sharing contract under a decentralized decision-making condition as follows:

$$
\left\{\begin{array}{l}
\pi_{R C}=\varphi_{1} \cdot R_{C}-\left(c_{1}+w_{1 C}\right) \cdot q-\alpha \cdot c(\theta) \\
\pi_{D C}=\varphi_{2} \cdot\left[\left(1-\varphi_{1}\right) \cdot R_{C}+w_{1 C} \cdot q\right]-\left(c_{2}+w_{2 C}\right) \cdot q-\beta \cdot c(\theta), \\
\pi_{M C}=\left(1-\varphi_{2}\right) \cdot\left[\left(1-\varphi_{1}\right) \cdot R_{C}+w_{1 C} \cdot q\right]+\left(w_{2 C}-c_{3}-c_{4}\right) \cdot q
\end{array}\right.
$$

where $R_{C}=p \cdot S(p, q, \theta)$ is the sales revenue of the retailer. We can obtain the optimal order quantity $q_{R C}^{*}$ based on the centralized decision-making derivation process:

$$
q_{R C}^{*}=F^{-1}\left(1-\frac{c_{1}+w_{1 C}}{\varphi_{1} \cdot p}\right)+y(p, \theta)
$$

Proof: see the Appendix.

Theorem 1. When:

$$
\left\{\begin{array}{l}
w_{1 C}=\varphi_{1} \cdot\left(c_{2}+c_{3}+c_{4}\right)+\left(\varphi_{1}-1\right) \cdot c_{1} \\
w_{2 C}=\varphi_{2} \cdot\left(c_{3}+c_{4}\right)-\left(1-\varphi_{2}\right) \cdot c_{2} \\
\alpha=\varphi_{1}
\end{array}\right.
$$

the improved revenue-sharing contract could coordinate the supply chain to achieve the best supply chain.

Proof: see the Appendix.

The preceding analysis emphasizes that the revenue-sharing contract realizes the coordination of the supply chain of FAPs, that is, the overall optimum of the supply chain. The revenue-sharing contract has two goals. First, the revenue-sharing contract aims to achieve the result that the optimal solution for the supply chain is the Nash equilibrium of decisions made by enterprises in the supply chain. That is, the supply chain achieves the highest profit as manufacturers, distributors, and retailers pursue the highest interests. Moreover, no enterprise in the supply chain is able to achieve considerably high interests without the loss of interest of the other members in the same supply chain. Second, the revenue-sharing contract aims to achieve the result that members in the supply chain 
IMDS

117,9

1852

achieve higher interests than that without any contract by setting the proper contract parameters under the coordination of the supply chain.

The following equation is easy to deduce from Equations (3) and (8), $w_{1 C}$, and $w_{2}$ :

$$
\pi_{I}-\pi_{R C}-\pi_{D C}=\left(1-\varphi_{2}\right)\left(1-\varphi_{1}\right) R_{C}+\left(1-\varphi_{2}\right) w_{1 C} \cdot q+\left(c_{2}-c_{3}\right) \cdot q=\pi_{M C}
$$

Thereafter, we combine Equation (8), $\alpha=\varphi_{1}$, and $\beta=1-\alpha=1-\varphi_{1}$ to determine the relationships among the profit of the retailer, profit of the distributor in the contractual supply chain, and optimal profit under the centralized decision making by using the following equation:

$$
\left\{\begin{array}{l}
\pi_{R C}=\varphi_{1} \cdot \pi_{I} \\
\pi_{D C}=\varphi_{2}\left(1-\varphi_{1}\right) \cdot \pi_{I} \\
\pi_{M C}=\left(1-\varphi_{2}\right)\left(1-\varphi_{1}\right) \cdot \pi_{I} .
\end{array}\right.
$$

Theorem 2. After the supply chain based on the improved revenue-sharing contract obtains the overall coordination, the profit of each member of the contract supply chain is not less than the profit of each member in the non-contractual supply chain when the revenue-sharing contract parameters satisfy the inequalities:

$$
\left\{\begin{array}{l}
\max \left(\frac{\pi_{R S}}{\pi_{I}}, \frac{c_{1}}{c}\right)<\varphi_{1}=\alpha<1 \\
\max \left(\frac{\pi_{D S}}{\left(1-\varphi_{1}\right) \cdot \pi_{I}}, \frac{c_{2}}{c_{2}+c_{3}+c_{4}}\right)<\varphi_{2}<1 \\
\frac{\pi_{M S}}{\pi_{I}}<\left(1-\varphi_{1}\right)\left(1-\varphi_{2}\right) .
\end{array}\right.
$$

Thus, the supply chain achieves the Pareto optimality.

Proof: see the Appendix.

We can obtain $\theta_{I}^{*}, q_{I}^{*}$, and $\pi_{I}^{*}$. Equation (10) presents that we can determine the optimal profit of each member in the supply chain based on the improved revenue-sharing contract. Moreover, we can obtain the optimal transportation time $t_{I}^{*}=T \sqrt{1-\theta_{I}^{*}}-t_{0}$ from the distributor to the retailer based on the relationship between the optimal fresh factor and time $\theta(t)=1-\left(t+t_{0}\right)^{2} / T^{2}$.

\section{Case analysis}

The case mainly aims to prove that the improved revenue-sharing contract can coordinate the three-level FAP supply chain in IoT. Moreover, the effect of the demand price elasticity and transit time on the supply chain profit is analyzed and verified, and the results are discussed. The theoretical results are applied to practical cases, which can solve the actual problem of the FAP supply chain coordination and further improve the interests of enterprises and the quality of life of people.

Foshan Jushi Agricultural Development Co., Ltd is one of the leading agriculture enterprises that includes aquaculture, processing, and sales, as well as a modern agriculture demonstration base and IoT application research unit for the agricultural products supply chain of safety traceability. This company handles the intelligent management of Mandarinfish in IoT. With the help of RFID and sensors that monitor and record water temperature, humidity, and fish feeding, the information is shared in the entire supply chain 
through the internet. Each member can adjust the strategy in a timely manner. Since the implementation of IoT, the annual output of Mandarinfish has reached 5,000 tons, and most of them have been exported to the USA and European markets.

This study obtained the historical aquaculture sales data of Mandarinfish in July 2015 and the empirical data that adopted IoT from our cooperation company in Foshan City. The survey data show that the Mandarinfish sales cycle is at least one day, that is, the supplier delivers the products to the retailer daily. The customer feedback information shows that the minimum Mandarinfish freshness that customers could accept is 0.3. The freshness impact on sales is linear and stable when the Mandarinfish freshness is above 0.3. The parameters are as follows (price unit: USD per kg):

$$
\begin{aligned}
& c_{1}=0.6, c_{2}=0.4, c_{3}=7, c_{5}=1.5, c_{6}=1, c_{7}=1.4, c_{8}=0.75, \rho=1 / 20, \gamma=0.95, \\
& w_{1}=11.2, w_{2}=8.0, t_{0}=1, T=5, \sigma=400, \lambda=1, a=1,000, k=40, l=40
\end{aligned}
$$

Thus, $c=8.15, c_{4}=0.15$ :

(1) The preceding data indicate that the various parameters of the FAP supply chain under different decision-making conditions are determined (see Table I). The overall profit improved by 5.5 percent after the supply chain in IoT adopted the improved revenue-sharing contract, thereby indicating that this contract can coordinate the supply chain. However, the retail price of the non-contractual supply chain under a decentralized decision-making condition is higher than the retail price of the supply chain under a centralized decision-making condition. However, the freshness or order quantity demonstrated the opposite relationship, that is, the optimal order quantity $q_{I}^{*}>q_{S}^{*}$ and the optimal freshness $\theta_{I}^{*}>\theta_{S}^{*}$. The optimal retail price $p_{I}^{*}<p_{S}^{*}$ indicates that the non-contractual supply chain under a decentralized decision-making condition could not coordinate the supply chain.

Under the improved revenue-sharing contract, relationships between the wholesale prices of distributors or manufacturers and the revenue-sharing factors of retailers or distributors are shown in Figures 3 and 4, respectively. The two figures indicate that a positive correlation exists between wholesale price and revenue-sharing factor, that is, wholesale price increases as revenue-sharing factor increases. However, wholesale prices under the improved revenue-sharing contract

\begin{tabular}{|c|c|c|c|c|c|c|c|}
\hline Class & Retail price & Order quantity & Freshness & Transportation time & Profit & Rate of profit & \\
\hline \multicolumn{8}{|c|}{ System } \\
\hline C & 17.04 & 354.65 & & & $3,003.56$ & 1 & \\
\hline $\mathrm{S}$ & 18.77 & 277.09 & & & $2,860.71$ & 0.952 & \\
\hline \multicolumn{8}{|c|}{ Retailer } \\
\hline $\mathrm{C}$ & 17.04 & & 0.89 & 0.66 & $3,003.56 \varphi_{1}$ & $\varphi_{1}$ & \\
\hline $\mathrm{S}$ & 18.77 & & 0.697 & 1.75 & $1,846.53$ & 0.615 & \\
\hline \multicolumn{8}{|c|}{ Distributor } \\
\hline $\mathrm{C}$ & $8.15 \varphi_{1}-0.6$ & & 0.96 & 1 & $3,003.56 \varphi_{2}\left(1-\varphi_{1}\right)$ & $\varphi_{2}\left(1-\varphi_{1}\right)$ & \\
\hline $\mathrm{S}$ & 11.2 & & 0.96 & 1 & 778.53 & 0.259 & Table I. \\
\hline \multicolumn{7}{|c|}{ Manufacturer } & Various decision \\
\hline $\mathrm{C}$ & $7.4 \varphi_{2}-0.4$ & & 1 & 0 & $3,003.56\left(1-\varphi_{2}\right)\left(1-\varphi_{1}\right)$ & $\left(1-\varphi_{2}\right)\left(1-\varphi_{1}\right)$ & making parameters of \\
\hline $\mathrm{S}$ & 8.0 & & 1 & 0 & 235.53 & 0.078 & the FAP supply chain \\
\hline
\end{tabular}
are lower than those without any contract, which is the mathematical constraint and
Three-level supply chain coordination

1853 
IMDS

117,9

\section{4}

Figure 3.

The relationship between retailers' price and $\varphi_{1}$

Figure 4.

The relationship between distributors' price and $\varphi_{2}$
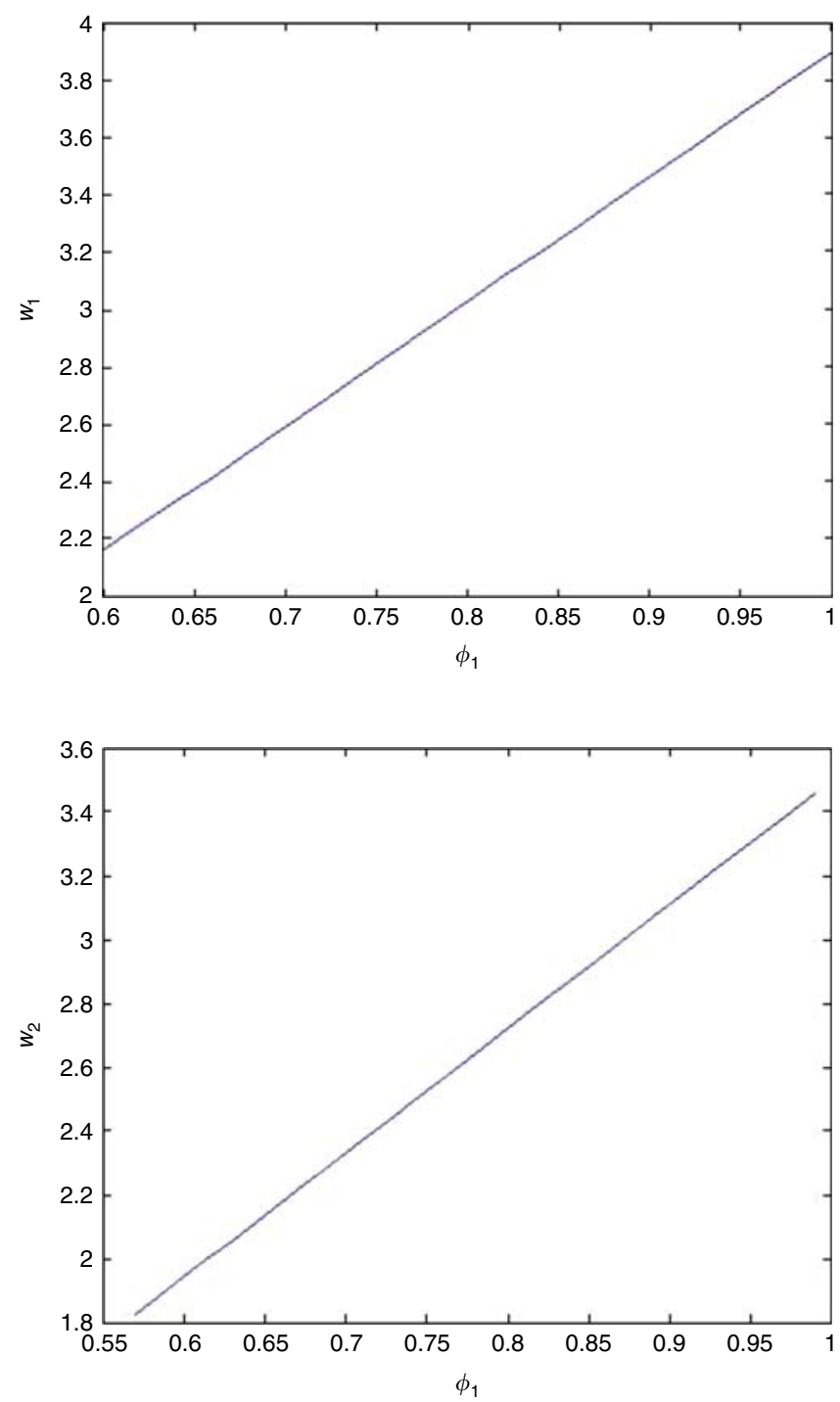

also the inherent requirement for the supply chain based on the improved revenuesharing contract.

(2) Table I shows that the profit of each member in the supply chain based on the improved revenue-sharing contract depends on the revenue-sharing coefficients $\varphi_{1}, \varphi_{2}$. From Theorem 2, we determine that (see Figure 5):

$$
\left\{\begin{array}{l}
0.615 \leqslant \varphi_{1}=\alpha<1 \\
0.259 \leqslant \varphi_{2}\left(1-\varphi_{1}\right)<1 \\
0.078 \geqslant\left(1-\varphi_{1}\right)\left(1-\varphi_{2}\right)
\end{array}\right.
$$




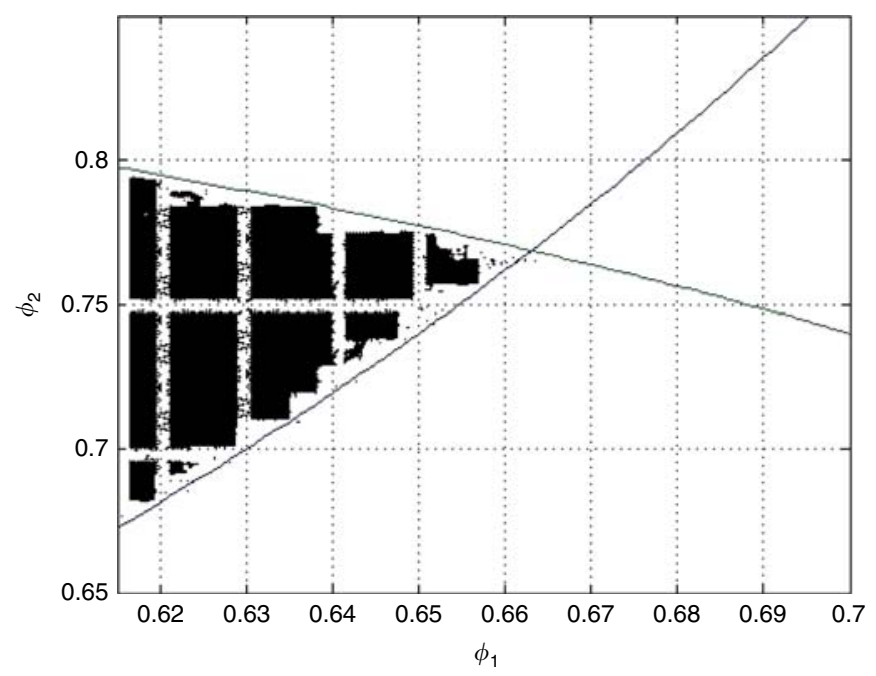

Three-level supply chain coordination

1855

Figure 5.

Revenue-sharing coefficients combined range

When $\varphi_{1}, \varphi_{2}$ are in the shaded area, the profit of every member in the supply chain based on the improved revenue-sharing contract is not less than the profit of each member of the non-contractual supply chain. The contractual supply chain achieves the Pareto optimality. All the supply chain members benefit as long as the revenue-sharing coefficients $\left(\varphi_{1}, \varphi_{2}\right)$ are within the shaded area in Figure 5. This range is conducive to the design of the improved revenue-sharing contract and the negotiation between the upstream and downstream enterprises of the supply chain.

(3) Equation (10) shows the relationship between the profits of the contractual supply chain members and revenue-sharing coefficient. Under the premise that the supply chain total profit is certain, the retailer profit is determined only by the retailer sharing coefficient. The profits of the distributor and manufacturer are dependent on the sharing coefficients of the retailer and distributor. We determine the several different combinations of the revenue-sharing coefficients in the range shown in Figure 5 and calculate the profit of each supply chain member. We obtain a set of data by setting different revenue-sharing coefficients (see Table II).

The relationship between the profits of the supply chain members and revenuesharing coefficient is shown in Figures 6-8. The relationship between the retailer's profit and the coefficient $\varphi_{1}$ is linear (see Figure 6). The profits of the distributor and manufacturer are jointly determined by the gain share coefficients of the retailer $\varphi_{1}$ and distributor $\varphi_{2}$, which are illustrated in Figures 7 and 8 as threedimensional curved surfaces.

\begin{tabular}{|c|c|c|c|c|c|c|}
\hline$\left(\varphi_{1}, \varphi_{2}\right)$ & $(0.62,0.77)$ & $(0.63,0.75)$ & $(0.64,0.72)$ & $(0.65,0.7)$ & $(0.66,0.68)$ & Table II. \\
\hline$\pi_{R C}$ & $1,862.21$ & $1,892.24$ & $1,922.28$ & $1,952.31$ & $1,982.35$ & Effects of revenue- \\
\hline$\pi_{D C}$ & 878.84 & 833.49 & 778.52 & 735.87 & 694.42 & sharing coefficients on \\
\hline$\pi_{M C}$ & 262.51 & 277.83 & 302.76 & 315.38 & 326.79 & the supply chain profits \\
\hline
\end{tabular}




\section{IMDS}

117,9

\section{6}

Figure 6.

Relationship between

the profit and

revenue-sharing

coefficient $\varphi_{1}$ of

the retailer

Figure 7.

Relationships between the profit and revenue-sharing coefficients of the distributor $\left(\varphi_{1}, \varphi_{2}\right)$
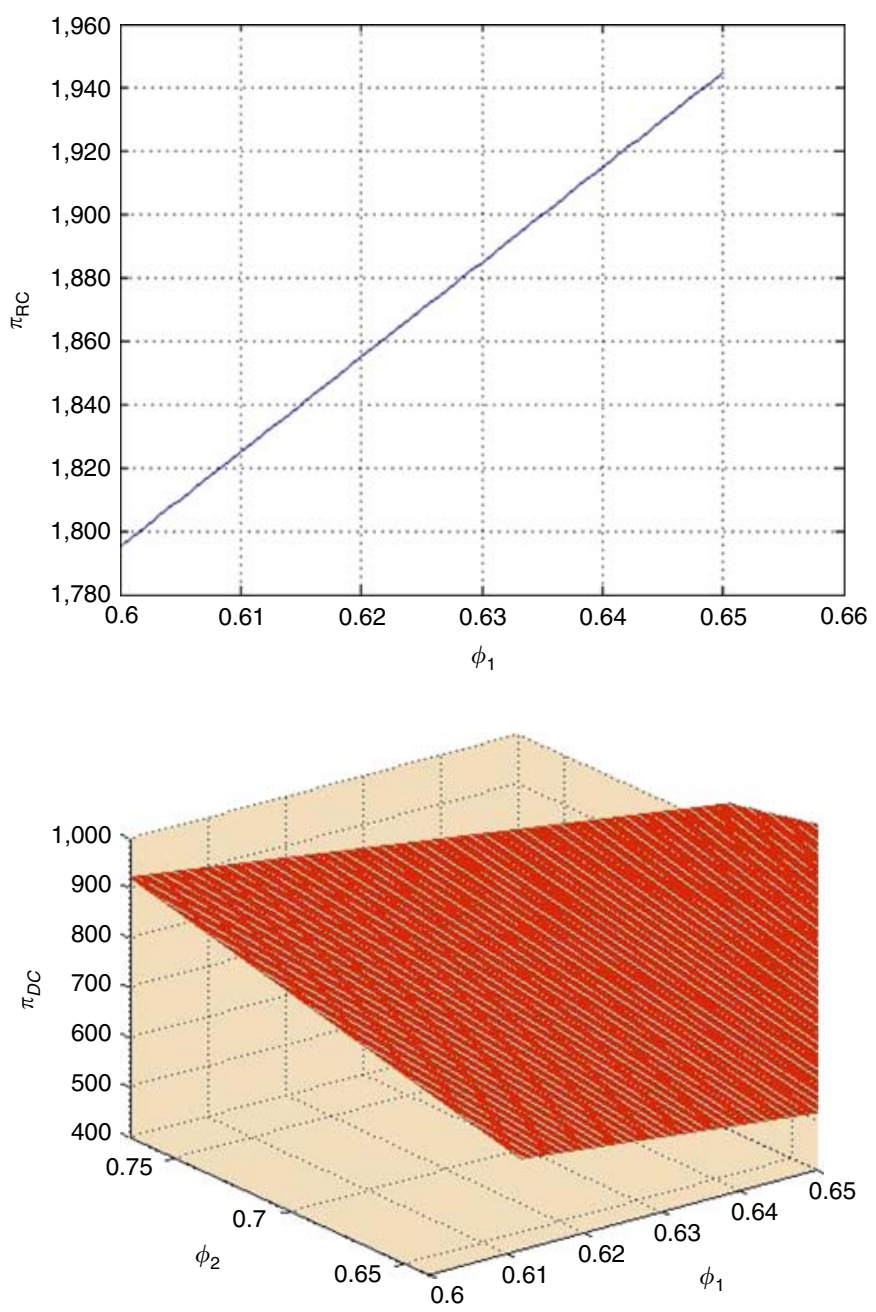

The retailer's profit is determined by its own revenue-sharing coefficient (see Figure 6) and a high-profit sharing coefficient of the retailer corresponds to a high profit.

In the range of the revenue-sharing coefficient, the profit of the distributors decreases as the retailers' profit sharing coefficient increases (see Figure 7). However, the distributor's profit increases as the distributor's revenue-sharing coefficient increases.

The manufacturer's profit decreases with the increase of the revenue-sharing coefficient of the retailers and distributor (see Figure 8). The revenue-sharing contract shows that high $\phi_{1}$ and $\phi_{2}$ correspond to limited benefits distributed to the upstream manufacturer and limited profits for the manufacturer.

(4) The price elasticity of demand has an effect on the supply chain profit. The optimal order quantity of the retailer and optimal freshness of the Mandarinfish pursued by the retailer are smaller when the price elasticity of demand is larger when a set of combined contract parameters is given (see Table III). All profits of the supply chain members are gradually reduced. The overall supply chain profit also decreases gradually. 


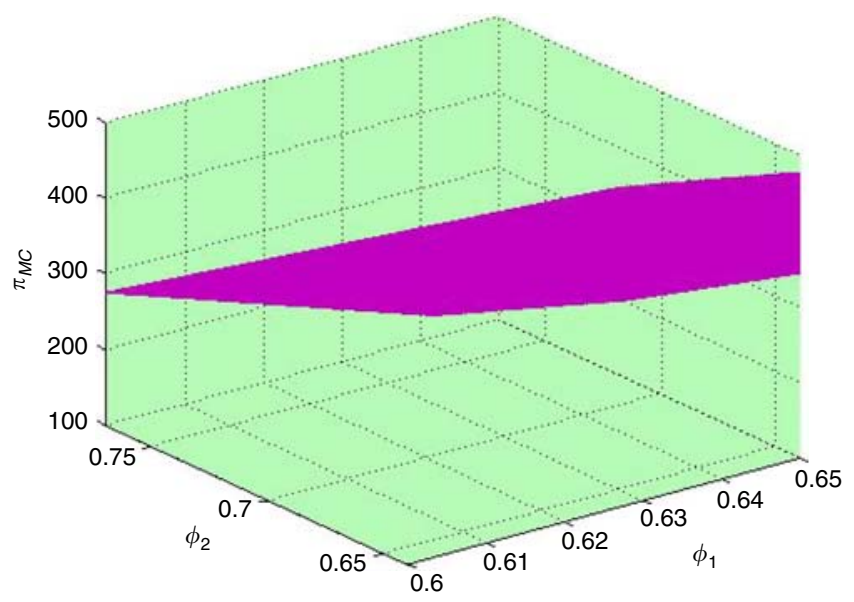

Three-level supply chain coordination

1857

Figure 8.

Relationships between

the profit and revenue-sharing coefficients of the manufacturer $\left(\varphi_{1}, \varphi_{2}\right)$

\begin{tabular}{llllllrr}
\hline$l$ & $q$ & $\theta$ & $\left(\varphi_{1}, w_{1}, \varphi_{2}, w_{2}\right)$ & $\pi_{R C}$ & $\pi_{D C}$ & $\pi_{M C}$ & Table III. \\
\hline 40 & 354.65 & 0.89 & $(0.65,4.7,0.7,4.78)$ & $1,952.31$ & 735.87 & 315.38 & Effect of price \\
45 & 331.4 & 0.74 & $(0.65,4.7,0.7,4.78)$ & $1,523.67$ & 574.31 & 246.13 & elasticity of demand \\
50 & 307.95 & 0.62 & $(0.65,4.7,0.7,4.78)$ & $1,195.5$ & 450.63 & 193.1 & on the supply chain \\
55 & 286.1 & 0.52 & $(0.65,4.7,0.7,4.78)$ & 939.37 & 354.07 & 151.74 & profit \\
\hline
\end{tabular}

(5) Influences of freshness elasticity on profits of supply chain. Given a set of contract parameters and influenced by the inherent constraint of freshness (below 1), the optimal order amount and optimal prices increase as the freshness factor $(k, \sigma)$ in the supply chain profit function increases. However, the profits of members in the supply chain slightly increase. Accordingly, freshness influences the demand for Mandarinfish in the market and the freshness control cost of Mandarinfish in transit transportation. A negative correlation exists between demand and cost. The freshness of Mandarinfish is not significant for market demand because freshness is within the scope of acceptance of customers. Moreover, the change of the freshness control cost of Mandarinfish in transit transportation has significant influence on control cost. The optimal profit is achieved under the balance of freshness and control cost. Table IV shows that as $(k, \sigma)$ changes in direction, the total profit changes in the same direction but the change of total profit is minimal.

(6) After determining the revenue-sharing coefficients under the improved revenue-sharing contract, we obtain a set of data that vary with changes in the transportation time to determine how the choices of contract parameters influence the supply chain parameters by setting different transportation times (Table V).

\begin{tabular}{lccccrrr}
\hline$(k, \sigma)$ & $q$ & $p$ & $\left(\varphi_{1}, w_{1}, \varphi_{2}, w_{2}\right)$ & $\pi_{R C}$ & $\pi_{D C}$ & $\pi_{M C}$ \\
\cline { 1 - 2 }$(40,400)$ & 354.65 & 17.04 & $(0.65,4.55,0.65,4.41)$ & $1,952.31$ & 683.31 & 367.94 & Table IV. \\
$(45,450)$ & 357.28 & 17.09 & $(0.65,4.55,0.65,4.41)$ & $1,936.35$ & 677.72 & 364.93 & Supply chain profit \\
$(50,500)$ & 359.65 & 17.15 & $(0.65,4.55,0.65,4.41)$ & $1,978.6$ & 692.51 & 372.89 & under different \\
$(55,550)$ & 361.90 & 17.22 & $(0.65,4.55,0.65,4.41)$ & $1,992.25$ & 697.29 & 375.46 & combinations of $(k, \sigma)$ \\
\hline
\end{tabular}


IMDS

117,9

\section{8}

Table V. Supply chain profit under different transport times
We determine that the longer transportation time from the distributor to the retailer results in lower freshness, and a lower retail price results in larger order quantities. The total profit shows a decreasing trend.

The relationship between optimal profits and combinations of contract parameters can be achieved. The total profits under different combinations of freshness and prices are shown in Figure 9.

Figure 9 shows that the highest expected profit increases as price and freshness increase within a certain range. A three-dimensional graph showing the relationship between profits and combinations of freshness (or price) and order amount can also be achieved.

\section{Conclusions}

This study investigated the FAP supply chain in IoT and constructed the freshness function $\theta(t)=1-\left(\left(t+t_{0}\right)^{2} /\left(T^{2}\right)\right)$. Considering the perishable nature of FAP, we developed the market demand function under the influence of freshness and prices based on the survey results. We analyzed the coordination of a FAP supply chain that comprises a manufacturer, distributor, and retailer based on an improved revenue-sharing contract. The accuracy of the model is verified through a case analysis, thereby providing a theoretical guide for the coordination of supply chains. The main results are as follows:

(1) IoT plays an important role in the FAP supply chain, enhances the quality of FAP, reduces the damage and accident rates, and ensures supply chain information

\begin{tabular}{lcccccc} 
Transportation & Freshness & Freshness control costs & Retail price & $y(\phi, \theta)$ & Order amount & Total profit time \\
\hline 0.5 & 0.91 & 165.62 & 17.25 & 346.4 & 347.05 & $3,001.83$ \\
1 & 0.84 & 141.12 & 16.55 & 371.6 & 372.25 & $2,994.51$ \\
1.5 & 0.75 & 112.5 & 15.65 & 404 & 404.65 & $2,930.30$ \\
2 & 0.64 & 81.92 & 14.55 & 443.6 & 444.25 & $2,768.25$ \\
2.5 & 0.51 & 52.02 & 13.25 & 490.4 & 491.05 & $2,458.11$ \\
3 & 0.36 & 25.92 & 11.75 & 544.4 & 545.05 & $1,940.54$ \\
\hline
\end{tabular}

Figure 9.

Supply chain profit under the combinations of fresh degrees and prices

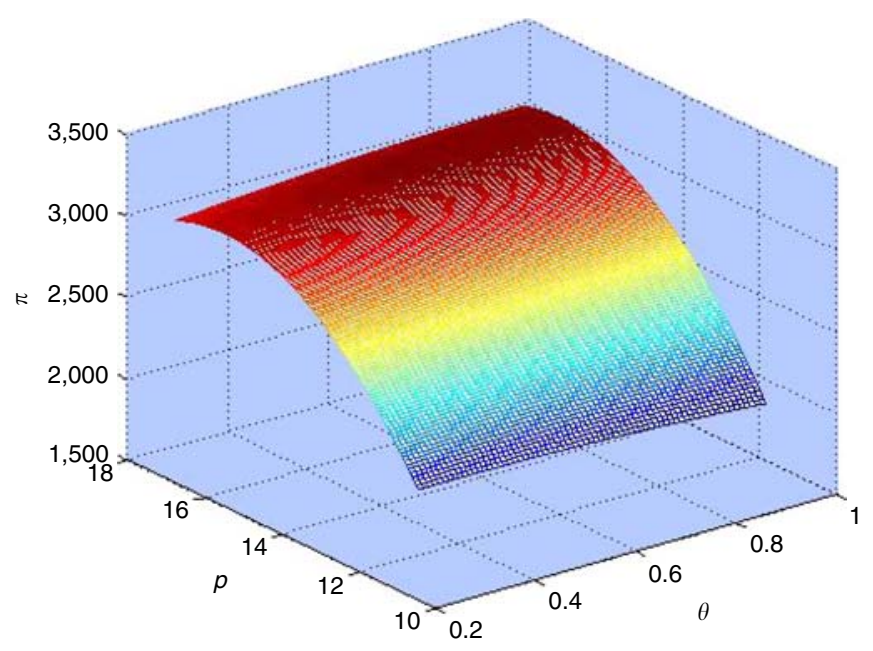


sharing by means of real-time control in transit and safety management. These factors are beneficial to supply chain coordination.

(2) A comparison among the supply chains under three types of decision-making situations indicates that the improved revenue-sharing contract can coordinate the supply chain and benefit all enterprises in the supply chain in IoT. Under a certain combination of revenue-sharing contract parameters, the maximum expected profit of the supply chain can be arbitrarily assigned among the manufacturers, distributors, and retailer. The specific value is decided by the importance and bargaining power of the manufacturer, distributor, and retailer in the supply chain.

(3) The price elasticity of market demand has immense influence on the profit of the supply chain. Through empirical analysis, we determine that the change of the price elasticity of FAPs significantly affects the supply chain profit. With the increase of the price elasticity, market demand, optimal order quantity, and freshness are gradually reduced, thereby decreasing the maximum expected profit of the supply chain as well. Moreover, the profits of all supply chain members, regardless of manufacturers, distributors or retailers, are gradually reduced; thus, the reasonable pricing is important in the sale of FAPs. Enterprises should adjust their decisions according to the change of market demands to maximize profits when managing.

(4) We concluded through the further analysis of the optimal profit that the optimal profit decreases with the increase of transit time and freshness reduction. Moreover, guaranteeing that FAP is smooth and efficient in transportation is necessary to obtain substantial profits. Furthermore, the transit time and environment need to be controlled strictly to create an efficient logistics chain, which is supported by using the IoT technology.

However, this study only considered the transport time $t$ between the distributors and retailer and regarded the bulk transportation time $t_{0}$ as a constant between the manufacturer and the distributor in the freshness of the demand function. We also assumed that the freshness control cost is undertaken by the retailer and distributor. We attempted to regard $t_{0}$ as a variable and analyzed the coordination when the freshness control cost of the entire process is undertaken by different supply chain members.

Huge fresh produce wastage has always been a challenge for the business. It is way much easier to have a qualitative description on wastage than to have a quantitative one. Using IT to quantify the research is a doable solution. Note that the function expression of freshness is the vital base on which this paper rely. Since freshness is an ambiguous concept, determined by people through things like product appearance, color, there is not yet any standard technique or approach for identification, making it one of the directions for future research.

We also studied the coordination of the FAP supply chain in IoT and information symmetry. In the future, we will further discuss coordination based on the improved contract constraints in Io $\mathrm{T}$ and emergent events.

\section{Acknowledgments}

This work was supported by Program (71172075) and Major International (Regional) Joint Research Project (71420107024) of Natural Science Foundation of China, Guangdong Natural Science Foundation (2016A030313485, 2017A030313415), Guangdong Soft Science Research Project (2015A070704005), Guangdong "12th Five-Year" Philosophy and Social Sciences Planning Project (GD15CGL15), Guangdong Science and Technology Planning Project (2013B040500007, 2013B040200057), and Fundamental Research Funds for the Central Universities (2015KXKYJ02).
Three-level supply chain coordination 
IMDS

117,9

1860

\section{References}

Ahumada, O., Villalobos, J.R. and Mason, A.N. (2012), "Tactical planning of the production and distribution of fresh agricultural products under uncertainty", Agricultural Systems, Vol. 112 No. 13, pp. 17-26.

Al-Busaidi, M.A., Jukes, D.J. and Bose, S. (2016), "Seafood safety and quality: an analysis of the supply chain in the Sultanate of Oman", Food Control, Vol. 59, January, pp. 651-662.

Arshinder, K., Kanda, A. and Deshmukh, S.G. (2011), "A review on supply chain coordination: coordination mechanisms, managing uncertainty and research directions", in Choi, T.M. and Cheng, T. (Eds), Supply Chain Coordination Under Uncertainty, International Handbooks on Information Systems, Springer, Berlin and Heidelberg.

Bellantuono, N., Giannoccaro, I. and Pontrandolfo, P. (2011), "Coordination of the supplier-retailer relationship in a multi-period setting: the additional ordering cost contract", in Choi, T.M. and Cheng, T. (Eds), Supply Chain Coordination Under Uncertainty, International Handbooks on Information Systems, Springer, Berlin and Heidelberg.

Cai, X. and Zhou, X. (2014), "Optimal policies for perishable products when transportation to export market is disrupted", Production \& Operations Management, Vol. 23 No. 5, pp. 907-923.

Cai, X., Chen, J., Xiao, Y., Xu, X. and Yu, G. (2013), "Fresh-product supply chain management with logistics outsourcing", Omega, Vol. 41 No. 4, pp. 752-765.

Choi, T.M. and Cheng, T.C.E. (2011), Supply Chain Coordination Under Uncertainty, International Handbooks on Information Systems, Springer, Berlin and Heidelberg.

Donis-González, I.R., Guyer, D.E., Pease, A. and Barthel, F. (2014), "Internal characterisation of fresh agricultural products using traditional and ultrafast electron beam x-ray computed tomography imaging”, Biosystems Engineering, Vol. 117 No. 1, pp. 104-113.

Grunow, M. and Piramuthu, S. (2013), "RFID in highly perishable food supply chains - remaining shelf life to supplant expiry date?", International Journal of Production Economics, Vol. 146 No. 2, pp. 717-727.

Gunasekaran, A., Papadopoulos, T., Dubey, R., Wamba, S.F., Childe, S.J., Hazen, B. and Akter, S. (2016), "Big data and predictive analytics for supply chain and organizational performance", Journal of Business Research, Vol. 70, pp. 308-317.

He, Y., Zhao, X., Zhao, L. and He, J. (2009), "Coordinating a supply chain with effort and price dependent stochastic demand”, Applied Mathematical Modelling, Vol. 33 No. 6, pp. 2777-2790.

Heese, H.S. (2011), "Inventory Record inaccuracy, RFID technology adoption and supply chain coordination", in Choi, T.M. and Cheng, T. (Eds), Supply Chain Coordination Under Uncertainty, International Handbooks on Information Systems, Springer, Berlin and Heidelberg.

Höhn, M.I. (2010), "Literature review on supply chain contracts”, in Höhn, M.I. (Ed.), Relational Supply Contracts, Volume 629 of the Series Lecture Notes in Economics and Mathematical Systems, Springer, Berlin and Heidelberg, pp. 19-34.

Hong, I.H., Dang, J.F., Tsai, Y.H., Liu, C.S., Lee, W.T., Wang, M.L. and Chen, P.C. (2011), “An RIFD application in the food supply chain: a case study of convenience stores in Taiwan", Journal of Food Engineering, Vol. 106 No. 2, pp. 119-126.

Krishnan, H. and Winter, R.A. (2011), "On the role of revenue-sharing contracts in supply chains", Operations Research Letters, Vol. 39 No. 1, pp. 28-31.

Lee, Y.P. and Dye, C.Y. (2012), "An inventory model for deteriorating items under stock-dependent demand and controllable deterioration rate”, Computers \& Industrial Engineering, Vol. 63 No. 63, pp. 474-482.

Li, F., Han, Y. and Jin, C. (2016), "Practical access control for sensor networks in the context of the internet of things", Computer Communications, Vols 89-90, pp. 154-164.

Lin, L., Yang, S.P. and Dan, B. (2011), "Three-level supply chain coordination of fresh agricultural products with time constraints", Chinese Journal of Management Science, Vol. 19 No. 3, pp. 55-62. 
Lin, L.I. and Fan, T.J. (2014), "Research on decision-making of fresh agricultural product supply chain with RFID technology”, Xi Tong Gong Cheng Li Lun Yu Shi Jian/System Engineering Theory \& Practice, Vol. 34 No. 4, pp. 836-844.

Lohmann, J.C. (2010), "Coordination of supply chain investments and the advantage of revenue sharing", Journal of Business Economics, Vol. 80 No. 9, pp. 969-990.

Lu, S., Xu, C. and Zhong, R.Y. (2016), "An active RFID tag-enabled locating approach with multipath effect elimination in AGV", IEEE Transactions on Automation Science \& Engineering, Vol. 13 No. 3, pp. 1333-1342.

Maralit, B.A., Aguila, R.D., Ventolero, M.F.H., Perez, S.K.L., Willette, D.A. and Santos, M.D. (2013), "Detection of mislabeled commercial fishery by-products in the Philippines using DNA barcodes and its implications to food traceability and safety", Food Control, Vol. 33 No. 1, pp. 119-125.

Nahmias, S. (1982), "Perishable inventory theory: a review", Operations Research, Vol. 30 No. 4, pp. 680-708.

Narsimhalu, U., Potdar, V. and Kaur, A. (2015), "A case study to explore influence of traceability factors on Australian food supply chain performance", Procedia-Social and Behavioral Sciences, Vol. 189, pp. 17-32.

Ouardighi, F.E. (2014), "Supply quality management with optimal wholesale price and revenue sharing contracts: a two-stage game approach", International Journal of Production Economics, Vol. 156 No. 5, pp. 260-268.

Qin, Y., Wang, J. and Wei, C. (2014), "Joint pricing and inventory control for fresh produce and foods with quality and physical quantity deteriorating simultaneously", International Journal of Production Economics, Vol. 152 No. 2, pp. 42-48.

Rekik, Y., Sahin, E. and Dallery, Y. (2009), "Inventory inaccuracy in retail stores due to theft: an analysis of the benefits of RFID", International Journal of Production Economics, Vol. 118 No. 1, pp. 189-198.

Ruiz-Garcia, L. and Lunadei, L. (2011), "The role of RFID in agriculture: applications, limitations and challenges", Computers \& Electronics in Agriculture, Vol. 79 No. 1, pp. 42-50.

Sana, S.S. (2010), "Demand influenced by enterprises' initiatives - a multi-item EOQ model of deteriorating and ameliorating items", Mathematical \& Computer Modelling, Vol. 52 Nos 1-2, pp. 284-302.

Shen, D., Lai, K.K., Leung, S. and Liang, L. (2011), "Modelling and analysis of inventory replenishment for perishable agricultural products with buyer-seller collaboration", International Journal of Systems Science, Vol. 42 No. 7, pp. 1207-1217.

Tendyck, H. (2015), "Communications in a low energy internet of things", Electronics World, Vol. 121 No. 1946, pp. 14-15.

Verdouw, C.N., Wolfert, J., Beulens, A.J.M. and Rialland, A. (2016), "Virtualization of food supply chains with the internet of things", Journal of Food Engineering, Vol. 176 No. 1, pp. 128-136.

Voigt, G. and Inderfurth, K. (2011), "Supply chain coordination and setup cost reduction in case of asymmetric information", OR Spectrum, Vol. 33 No. 1, pp. 99-122.

Yan, B., Yan, C., Ke, C. and Tan, X. (2016), "Information sharing in supply chain of agricultural products based on the internet of things", Industrial Management \& Data Systems, Vol. 116 No. 7, pp. 1397-1416.

Yan, B., Shi, S., Ye, B., Zhou, X. and Shi, P. (2015), "Sustainable development of the fresh agricultural products supply chain through the application of RFID technology", Information Technology \& Management, Vol. 16 No. 1, pp. 67-78.

Yang, A.T. and Zhao, L.D. (2011), "Supply chain network equilibrium with revenue sharing contract under demand disruptions", International Journal of Automation \& Computing, Vol. 8 No. 2, pp. 177-184.

Yu, M. and Nagurney, A. (2012), "Competitive food supply chain networks with application to fresh produce”, European Journal of Operational Research, Vol. 224 No. 2, pp. 273-282. 
IMDS

117,9

1862

Yu, Y., Wang, Z. and Liang, L. (2012), "A vendor managed inventory supply chain with deteriorating raw materials and products", International Journal of Production Economics, Vol. 136 No. 2, pp. 266-274.

Zhang, W.G., Fu, J., Li, H. and Xu, W. (2012), "Coordination of supply chain with a revenue-sharing contract under demand disruptions when retailers compete", International Journal of Production Economics, Vol. 138 No. 1, pp. 68-75.

Zhong, R.Y., Huang, G.Q., Lan, S., Dai, Q.Y., Zhang, T. and Xu, C. (2015), "A two-level advanced production planning and scheduling model for RFID-enabled ubiquitous manufacturing", Advanced Engineering Informatics, Vol. 29 No. 4, pp. 799-812.

\section{Appendix}

Proof of $q_{S}^{*}$ in Section 4.3.

To evaluate the profits of retailers, distributors, and manufacturers, the optimal order quantity $q_{S}^{*}$ is evaluated when $\pi_{R S}$ is at its optimum, as well as placed in the function of the distributor profit, to evaluate $w_{1 S}^{*}$, which is the optimal wholesale of the distributors, when $\pi_{D S}$ is at its optimum; use $q_{S}^{*}$ and $w_{1 S}^{*}$ in evaluating $\pi_{M S}$, which is the optimum of the manufacturer profit function, to evaluate $w_{2 S}^{*}$; and then place $w_{2 S}^{*}$ into $w_{1 S}^{*}$, which leads to all the optimal profits.

The preceding process considers the partial derivatives of $\pi_{R S}$ on freshness $\theta$, price $p$, and order quantity $q$ as follows:

$$
\begin{gathered}
\frac{\partial \pi_{R S}}{\partial \theta}=p \cdot \frac{\partial S(p, q, \theta)}{\partial \theta}-c^{\prime}(\theta)=p \cdot k \cdot F[q-y(p, \theta)]-\sigma \cdot \theta \\
\frac{\partial \pi_{R S}}{\partial p}=S(p, q, \theta)+p \cdot \frac{\partial S(p, q, \theta)}{\partial p}=S(p, q, \theta)-p \cdot l \cdot F[q-y(p, \theta)] \\
\frac{\partial \pi_{R S}}{\partial q}=p \cdot \frac{\partial S(p, q, \theta)}{\partial q}-c_{1}-w_{1 S}=p \cdot[1-F(q-y(p, \theta))]-c_{1}-w_{1 S}
\end{gathered}
$$

The partial derivatives of the preceding three formulas are considered as follows:

$$
\begin{gathered}
\frac{\partial^{2} \pi_{R S}}{\partial \theta^{2}}=p \cdot \frac{\partial^{2} S(p, q, \theta)}{\partial \theta^{2}}-c^{\prime \prime}(\theta)=-p \cdot k^{2} f[q-y(p, \theta)]-\sigma<0 \\
\frac{\partial^{2} \pi_{R S}}{\partial p^{2}}=2 \cdot \frac{\partial S(p, q, \theta)}{\partial p}+p \cdot \frac{\partial^{2} S(p, q, \theta)}{\partial p^{2}}=-2 \cdot l \cdot F[q-y(p, \theta)]-p \cdot l^{2} f[q-y(p, \theta)]<0 \\
\frac{\partial^{2} \pi_{R S}}{\partial q^{2}}=p \cdot \frac{\partial^{2} S(p, q, \theta)}{\partial q^{2}}=-p \cdot f[q-y(p, \theta)]<0
\end{gathered}
$$

The partial derivatives of the second order of $\pi_{R S}$ on $\theta, p, q$ enable us to determine that $\left(\partial^{2} \pi_{R S}\right) /\left(\partial \theta^{2}\right)$, $\left(\partial^{2} \pi_{R S}\right) /\left(\partial p^{2}\right),\left(\partial^{2} \pi_{R S}\right) /\left(\partial q^{2}\right)$ is negative, that is, $\pi_{R S}$ is a strict concave function. When the retail profit is at its profit, the optimum $\left(\theta_{S}^{*}, p_{S}^{*}, q_{S}^{*}\right)$ needs to agree that formulas (A1)-(A3) are equal to 0 .

Accordingly, we learn that $q_{S}^{*}, \theta_{S}^{*}, p_{S}^{*}$ needs to agree with the following formulas:

$$
\begin{gathered}
q_{S} *=F^{-1}\left(1-\frac{c_{1}+w_{1 S}}{p}\right)+y(p, \theta) \\
\theta_{S} *=\frac{k\left(p-c_{1}-w_{1 S}\right)}{\sigma}
\end{gathered}
$$




$$
p_{S} *=\frac{-\left[a+\frac{1}{\lambda}+\left(l-\frac{k^{2}}{\sigma}\right)\left(c_{1}+w_{1 S}\right)\right]+\sqrt{\left[a+\frac{1}{\lambda}+\left(l-\frac{k^{2}}{\sigma}\right)\left(c_{1}+w_{1 S}\right)\right]^{2}-4\left(\frac{k^{2}}{\sigma}-2 l\right) \frac{\left(c_{1}+w_{1 S}\right)}{\lambda}}}{2\left(\frac{k^{2}}{\sigma}-2 l\right)}
$$

Proof of $q_{R C}^{*}$ in Section 4.4 .

The optimum solution $\left(q_{C}^{*}, p_{C}^{*}, \theta_{C}^{*}\right)$ needs to agree that the partial derivative of $\pi_{R C}$ on order quantity, retail price, freshness is equal to 0 :

$$
\begin{gathered}
\frac{\partial \pi_{R C}}{\partial q}=\varphi_{1} \cdot p \cdot \frac{\partial S(p, q, \theta)}{\partial q}-c_{1}-w_{1 C}=\varphi_{1} \cdot p \cdot[1-F(q-y(p, \theta))]-c_{1}-w_{1 C} \\
\frac{\partial \pi_{R C}}{\partial p}=\varphi_{1} \cdot\left[S(p, q, \theta)+p \cdot \frac{\partial S(p, q, \theta)}{\partial p}\right]=\varphi_{1} \cdot[S(p, q, \theta)-p \cdot l \cdot F[q-y(p, \theta)]] \\
\frac{\partial \pi_{R C}}{\partial \theta}=\varphi_{1} \cdot p \cdot \frac{\partial S(p, q, \theta)}{\partial \theta}-\alpha \cdot c^{\prime}(\theta)=\varphi_{1} \cdot p \cdot k \cdot F[q-y(p, \theta)]-\alpha \cdot \sigma \cdot \theta
\end{gathered}
$$

The partial derivatives of the preceding three formulas are considered as follows:

$$
\begin{gathered}
\frac{\partial^{2} \pi_{R C}}{\partial \theta^{2}}=\varphi_{1} \cdot p \cdot \frac{\partial^{2} S(p, q, \theta)}{\partial \theta^{2}}-\alpha \cdot c^{\prime \prime}(\theta)=-\varphi_{1} \cdot p \cdot k^{2} f[q-y(p, \theta)]-\alpha \cdot \sigma<0 \\
\frac{\partial^{2} \pi_{R C}}{\partial p^{2}}=2 \varphi_{1}\left[\frac{\partial S(p, q, \theta)}{\partial p}+p \cdot \frac{\partial^{2} S(p, q, \theta)}{\partial p^{2}}\right]=-2 \varphi_{1}\left[l \cdot F[q-y(p, \theta)]-p \cdot l^{2} f[q-y(p, \theta)]\right]<0 \\
\frac{\partial^{2} \pi_{R C}}{\partial q^{2}}=p \cdot \varphi_{1} \cdot \frac{\partial^{2} S(p, q, \theta)}{\partial q^{2}}=-p \cdot \varphi_{1} \cdot f[q-y(p, \theta)]<0 .
\end{gathered}
$$

The partial derivatives of the second order of $\pi_{R C}$ on $\theta, p, q$ enable us to determine that $\left(\partial^{2} \pi_{R C}\right) /\left(\partial \theta^{2}\right)$, $\left(\partial^{2} \pi_{R C}\right) /\left(\partial p^{2}\right),\left(\partial^{2} \pi_{R C}\right) /\left(\partial q^{2}\right)$ is negative, that is, $\pi_{R C}$ is their strict concave function. When the retail profit is at its profit, the optimum $\left(\theta_{R C}^{*}, p_{R C}^{*}, q_{C}^{*}\right)$ needs to agree that formulas (A10)-(A.12) are equal to 0 .

Accordingly, we learn that the optimal quantity order $q_{R C}{ }^{*}$ needs to agree with the following formula:

$$
q_{R C} *=F^{-1}\left(1-\frac{c_{1}+w_{1 C}}{\varphi_{1} \cdot p}\right)+y(p, \theta) .
$$

Proof of Theorem 1.

To enable the improved revenue-sharing contract to coordinate the supply chain, the optimal solution of the improved revenue-sharing contract supply chain must be equal to the optimal solution of the supply chain under the centralized decision-making condition. That is, $q_{R C}^{*}=q_{I}^{*}, p_{R C}^{*}=p_{I}^{*}, \theta_{C}^{*}=\theta_{I}^{*}$. Determining the second-order partial derivatives on the order quantity, retail price, and freshness of the retailer profit is easy based on the centralized decision-making derivation process. All the second-order partial derivatives are below 0 , and the profits of the retailer are the concave function of retail price and freshness. When the retailer obtains the optimal profit, the optimal solution $\left(q_{C}^{*}, p_{C}^{*}, \theta_{C}^{*}\right)$ needs to meet the partial derivative requirements of $\pi_{R C}$ with the order quantity, retail price, and freshness equal to 0 . That is:

$$
\left\{\begin{array}{l}
\frac{\partial \pi_{R C}}{\partial q_{C}^{*}}=\varphi_{1} \cdot p \cdot \frac{\partial S\left(p, q_{C}^{*}, \theta\right)}{\partial q_{C}^{*}}-c_{1}-w_{1 C}=0 \\
\frac{\partial \pi_{R C}}{\partial p_{C}^{*}}=\varphi_{1} \cdot\left[S\left(p_{C}^{*}, q, \theta\right)+p \cdot \frac{\partial S\left(p_{C}^{*}, q, \theta\right)}{\partial p_{C}^{*}}\right]=0 \\
\frac{\partial \pi_{R C}}{\partial \theta_{C}^{*}}=\varphi_{1} \cdot p \cdot \frac{\partial S\left(p, q, \theta_{C}^{*}\right)}{\partial \theta_{C}^{*}}-\alpha \cdot c^{\prime}\left(\theta_{C}^{*}\right)=0 .
\end{array}\right.
$$

By comparing Equations (A17) and (4), we know that $q_{R C}^{*}=q_{I}^{*}$ when $w_{1 C}=\varphi_{1} \cdot\left(c_{2}+c_{3}+c_{4}\right)+\left(\varphi_{1}-1\right) \cdot c_{1}$; and $\theta_{C}^{*}=\theta_{I}^{*}$ when $\alpha=\varphi_{1}$. The optimal retail price $p_{C}{ }^{*}$ selected by the retailer under the improved 
revenue-sharing contract must meet the best price in the centralized decision making. That is, the contract parameters change under the improved revenue-sharing contract. The retailer would select the optimal price in the centralized decision making as the retail price. Therefore, the improved revenue-sharing contract can achieve supply chain coordination.

From $q_{R C}^{*}=q_{I}^{*}$, the order in the profit function of the distributor under the improved revenuesharing contract needs to focus on the order quantity of decision making to achieve supply chain coordination. When the profit of the distributor is optimal, the equation is expressed as follows:

$$
\frac{\partial \pi_{D C}}{\partial q}=\varphi_{2} \cdot\left\{\left(1-\varphi_{1}\right) \cdot p \cdot \frac{\partial S(p, q, \theta)}{\partial q}+w_{1 C}\right\}-c_{2}-w_{2 C}=0 .
$$

The optimal order quantity $q_{D C}^{*}$ should adhere to the following equation:

$$
q_{D C} *=F^{-1}\left(1-\frac{c_{2}+w_{2 C}-\varphi_{2} \cdot w_{1 C}}{p \cdot \varphi_{2} \cdot\left(1-\varphi_{1}\right)}\right)+y(p, \theta)
$$

A comparison between Equations (A.19) and (5) indicates that determining that $q_{D C}^{*}=q_{I}^{*}=q_{R C}^{*}$ is easy when $w_{2 C}=\varphi_{2} \cdot\left(c_{3}+c_{4}\right)-\left(1-\varphi_{2}\right) \cdot c_{2}$, which is the proof.

Proof of Theorem 2.

To achieve the Pareto optimality of the supply chain, the profit of a member in the contractual supply chain should not be below its profit in the non-contractual supply chain under a decentralized decision-making condition. That is:

$$
\left\{\begin{array}{l}
\pi_{R C} \geqslant \pi_{R S} \\
\pi_{D C} \geqslant \pi_{D S} \\
\pi_{M C} \geqslant \pi_{M S} .
\end{array}\right.
$$

From these equations, we could obtain:

$$
\left\{\begin{array}{l}
\varphi_{1} \geqslant \frac{\pi_{R S}}{\pi_{I}} \\
\varphi_{2} \geqslant \frac{\pi_{D S}}{\left(1-\varphi_{1}\right) \cdot \pi_{I}} \\
\left(1-\varphi_{1}\right)\left(1-\varphi_{2}\right)>\frac{\pi_{M S}}{\pi_{I}} .
\end{array}\right.
$$

Considering that $w_{1 C}$ and $w_{2 C}$ are both positive, we have:

$$
\left\{\begin{array}{l}
\varphi_{1}>\frac{c_{1}}{c} \\
\varphi_{2}>\frac{c_{2}}{c_{2}+c_{3}+c_{4}}
\end{array} .\right.
$$

When the supply chain achieves a win-win situation, the ranges of the revenue-sharing parameters should satisfy the following conditions:

$$
\left\{\begin{array}{l}
\max \left(\frac{\pi_{R S}}{\pi_{I}}, \frac{c_{1}}{c}\right)<\varphi_{1}=\alpha<1 \\
\max \left(\frac{\pi_{D S}}{\left(1-\varphi_{1}\right) \cdot \pi_{I}}, \frac{c_{2}}{c_{2}+c_{3}+c_{4}}\right)<\varphi_{2}<1 \\
\frac{\pi_{M S}}{\pi_{I}}<\left(1-\varphi_{1}\right)\left(1-\varphi_{2}\right) .
\end{array}\right.
$$

Thus, Theorem 2 is proven. 


\section{About the authors}

Bo Yan is a Professor in School of Economics and Commerce at the South China University of Technology, China, where he received his $\mathrm{PhD}$ Degree in Mechanical Manufacturing and Automation in 2003. He worked as a Postdoctoral Researcher at the Department of Automation, Tsinghua University, from 2003 to 2005. His research interest includes supply chain. Bo Yan is the corresponding author and can be contacted at: yanbo@scut.edu.cn

Xiao-hua Wu is a Graduate Student at the South China University of Technology. Her major is in Logistics Engineering and Management, and her research interest includes E-commerce and supply chain management.

Bing Ye is a Graduate Student at the South China University of Technology. His major is in Logistics Engineering, and his research interest includes logistics and supply chain management.

Yong-wang Zhang graduated from the South China University of Technology and got a Master's Degree in Logistics Engineering. His research interest includes logistics and information system.
Three-level supply chain coordination

For instructions on how to order reprints of this article, please visit our website: 